\begin{tabular}{l} 
JOURNAL OF EMPOWERMENT \\
VOL. 2, No. 2, Desember 2021, h. 193-198 \\
ISSN 2580-0620 (Print) \\
ISSN 2597-9809 (Online) \\
Available Online at https://jurnal.unsur.ac.id/index.php/JE \\
\hline \hline
\end{tabular}

\title{
PENDAMPINGAN PENGEMBANGAN PEMASARAN DAN KEWIRAUSAHAN UMKM ULTRA MIKRO MELALUI PEMANFAATAN DIGITAL MARKETING
}

\section{MARKETING AND ENTREPRENEURSHIP DEVELOPMENT ASSISTANCE FOR ULTRA MICRO SMALL AND MEDIUM ENTERPRISES THROUGH USING DIGITAL MARKETING}

\author{
Widya Sari \\ Universitas Suryakancana \\ widya.sari@unsur.ac.id
}

\begin{tabular}{|l|l|l} 
Masuk: 16 Agustus 2021 & Penerimaan: 04 Desember 2021 & Publikasi: 31 Desember 2021 \\
\hline
\end{tabular}

\begin{abstract}
ABSTRAK
Kegiatan Kuliah Kerja Nyata (KKN) Tematik Kewirausahaan di Kelurahan Solokpandan, Kecamatan Cianjur, Kabupaten Cianjur,berlangsung selama satu bulan memfokuskan pada pengembangan Usaha Mikro Kecil Menengah (UMKM) Ultra Mikro (Umi). Permasalahan yang ditemui di kelurahan Solokpandan adalah kurangnya kesadaran para pelaku UMKM UMi tentang kegunaan digital marketing, mereka beranggapan bahwa digital marketing hanya merupakan tempat untuk terjadinya transaksi. Tujuan KKN Kewirausahaan ini adalah untuk : memberikan pemahaman, bimbingan, dan pelatihan digital marketing. Kegiatan ini dilakukan dengan metode pelatihan dan pendampingan penggunaan digital marketing Hasil dari rangkain kegiatan pengabdian ini adalah pengembangan salah satu produk UMKM UMi Keripik Singkong. Pelaku UMKM UMi didampingi telah mempunyai akun digital marketing dengan desain kemasan dan fotofoto produk yang menarik. Pendampingan yang dilakukan telah mampu meningkatkan kesadaran tentang pentingnya ilmu pengetahuan dan pemanfaatan teknologi sehingga akan meningkatkan kepercayaan diri pelaku usaha untuk bersaing di pasar digital.
\end{abstract}

Kata Kunci : Digital; Kewirausahaan; Pelatihan; Pendampingan.

\begin{abstract}
The Entrepreneurship Thematic Community Service Program (CSP) in Solokpandan Village, Cianjur District, Cianjur Regency, was held for 1 month, focuse on developing Ultra Micro Small and Medium Enterprises (UMi-MSME) The problem encountered in Solokpandan subdistrict was the lack of awareness of UMi-MSME about using of digital marketing, they tought that digital marketing is only a place for transactions. The objectives of this Entrepreneurship Community Service Program were to: provide understanding, guidance and training on digital marketing. This activity was carried out by training and mentoring methodes in the use of digital marketing. The result of this series of service activities was the development of one of the UMKM UMi cassava chips products. The UMi-MSME was accompanied by having a digital marketing account with attractive packaging designs and product photos. The assistance provided has been able to increase awareness of the importance of science and the use of technology so that it will increase the confidence of business actors to compete in the digital market.
\end{abstract}

Keywords $\quad$ : Digital; Entrepreneurship; Training; Accompaniment.

\section{A. PENDAHULUAN}

Pandemi Covid-19 telah menimbulkan economic shock, yang mempengaruhi ekonomi secara perorangan, rumah tangga, perusahaan mikro, kecil, menengah maupun besar, bahkan mempengaruhi ekonomi negara dengan skala cakupan dari lokal, nasional, dan bahkan global (Thaha, 2020). Seiring 
dengan berjalannya waktu, kebutuhan masyarakat semakin mengalami peningkatan, pertambahan penduduk yang semakin meningkat, kemajuan ilmu teknologi dan informasi, perubahan taraf hidup, dan derajat kebudayaan yang semakin maju hingga kebutuhan yang bervariasi dan beranekaragam membuat perkembangan ekonomi kreatif di arus pembangunan ekonomi modern ini khususnya pada masa pandemi seperti ini harus membuat inovasiinovasi sehingga membuat perkembangan ekonomi kreatif semakin meningkat (Syairozi \& Susanti, 2018).

Indonesia yang didominasi oleh keberadaan Usaha Mikro, Kecil, dan Menengah (UMKM) sebagai tulang punggung perekonomian nasional juga terdampak secara serius tidak saja pada aspek total produksi dan nilai perdagangan akan tetapi juga pada jumlah tenaga kerja yang harus kehilangan pekerjaannya karena wabah pandemik ini (Pakpahan, 2020). UMKM merupakan sektor usaha yang paling terpuruk. Hal ini juga yang menjadi salah satu penyebab pertumbuhan ekonomi Indonesia melambat (Aisyah, 2020), dan mengakibatkan pengangguran yang sangat tinggi, serta berdampak pada penurunan daya beli yang berpotensi menimbulkan peningkatan kemiskinan dan kelaparan (Prajanti et al., 2021).

Berbagai kajian terhadap UMKM terhadap beberapa daerah di Indonesia, juga menunjukkan kondisi yang tidak jauh berbeda. Seperti halnya di Kelurahan Solokpandan merupakan sebuah kelurahan yang berada di wilayah kecamatan Cianjur. Warga asli penduduk Kelurahan Solokpandan adalah berasal dari suku sunda, meskipun demikian masyarakat Kelurahan juga menggunakan bahasa Indonesia sehingga untuk berkomunikasi mereka tidak begitu sulit. Secara umum yang mendukung kemajuan Kelurahan Solokpandan yaitu infra struktur yang sudah memadai. Kelurahan Solokpandan mempunyai luas wilayah $\pm 66.345 \mathrm{Ha}$. Sebanyak $\pm 93 \%$ Kelurahan Solokpandan bermata pencaharian sebagai Pedagang atau didominasi oleh pelaku Usaha Mikro, Kecil, dan Menengah (UMKM) dan Ultra Mikro, seperti pelaku usaha makanan skala rumahan, seperti : keripik singkong, keripik tempe, makanan ringan, penjual lele segar dan bakso celup (baslup), serta banyak lagi pelaku usaha mikro lainnya. Sebagaimana dalam menghadapi persaingan perlu dilakukan perbaikan strategi oleh Usaha Mikro, Kecil dan Menengah (UMKM) dalam menghadapi kondisi tersebut, sehingga mampu bersaing dan memberikan kontribusi yang lebih besar bagi perekonomian Indonesia (Irwan Ch et al., 2020), yaitu dengan memanfaatkan kemajuan teknologi, internet dan komputer, hingga mampu menciptakan peluang bisnis berbasis online, baik skala mikro, kecil, menengah maupun besar bagi para calon pengusaha (Aris Fatoni \& Iwan Setyawan, 2020). Penggunaan digitial marketing tidak banyak disadari oleh pelaku bisnis, terutama para UKM di kelurahan Solokpandan. Kebanyakan mereka beranggapan bahwa digital marketing merupakan tempat untuk terjadinya transaksi, hal ini berbeda jauh dengan pengertian sebenarnya dari digitial marketing (Farell et al., 2019). Karena digital marketing ini merupakan pemanfaatan semua sumber daya yang berbeda pada internet sebagai tempat pemberi informasi sebagai produk-produk yang dimiliki oleh UKM tersebut. Tujuan KKN Kewirausahaan ini adalah untuk: 1). Memberikan pemahaman dan pengetahuan mengenai internet dan digital marketing. 2). Memberikan pelatihan untuk memanfaatkan media digital sebagai sarana untuk menentukan strategi pemasaran yang efektif dan efisien. 


\section{B. METODE}

Kegiatan pengabdian ini dilakukan di Kelurahan Solok Pandan Kecamatan Cianjur, Kabupaten Cianjur, pada tanggal 1-30 Agustus 2020. Para Peserta dalam kegiatan pengabdian ini terdiri dari para pelaku UMKM Ultra Mikro yang mempunyai usaha di bidang pengolahan makanan. Kegiatan pengabdian kepada masyarakat ini dilaksanakan dengan metode dalam bentuk penyampaian materi, diskusi, simulasi, dan praktik penggunaan digital marketing. Kegiatan pengabdian ini dilakukan dalam tiga tahap, yaitu (1) Prakegiatan, diisi dengan survey dan diskusi, (2)pelaksanaan kegiatan, meliputi penyampaian materi, (3) Pasca kegiatan, berupa evaluasi dalam bentuk pertanyaan interaktif maupun penilaian (tanggapan) terhadap materi yang telah disampaikan. Secara keseluruhan pelaksanaan pengabdian masyarakat ini dilaksanakan sesuai dengan jadwal pada Tabel 1.

Tabel 1. Jadwal Kegiatan

\begin{tabular}{|l|l|c|c|c|c|}
\hline \multirow{2}{*}{ No } & \multicolumn{1}{|c|}{ Kegiatan } & \multicolumn{3}{c|}{ Minggu ke - } \\
\cline { 3 - 5 } & & $\mathbf{1}$ & $\mathbf{2}$ & $\mathbf{3}$ & $\mathbf{4}$ \\
\hline 1 & Survey Pendahuluan & $\sqrt{ }$ & $\sqrt{ }$ & & \\
\hline 2 & Koordinasi dengan pihak kelurahan & $\sqrt{ }$ & $\sqrt{ }$ & & \\
\hline 3 & Identifikasi Masalah & & $\sqrt{ }$ & & \\
\hline 4 & Penyusunan Materi & & $\sqrt{ }$ & \\
\hline 5 & Pelatihan dan Evaluasi & & & $\sqrt{ }$ & $\sqrt{ }$ \\
\hline 6 & Laporan & & & $\sqrt{ }$ & $\sqrt{ }$ \\
\hline
\end{tabular}

Survey pendahuluan dilakukan oleh mahasiswa dengan mendatangi kantor lurah Solok pandan dan bersilaturahmi dengan Lurah serta aparat desa. diharapkan didapatkan informasi tentang demografi, kependudukan dan potensi desa. Setelah itu mahasiswa ditugaskan berpencar untuk survey ke masing-masing RT/RW yang ada dikelurahan Solokpandan. Hasil wawancara dengan pihak kelurahan dan hasil survey ke RT/RW kemudian didiskusikan dengan dosen pembimbing untuk melakukan identifikasi masalah. Selanjutnya disepakati masalah yang akan dijadikan objek kegiatan pengabdian yang kemudian dirumuskan menjadi materi pengabdian berupa pendampingan dan pelatihan. Kegiatan pendampingan dan pelatihan dilakukan di kantor Lurah dan di rumah warga yang akan menjadi mitra pengabdian, dan pelatihan berlangsung selama dua minggu dengan rincian dua jam/hari. Tahap akhir dari kegiatan pengabdian ini adalah monitoring dan evaluasi yang dilakukan dalam dua tahap oleh mahasiwa, yaitu tahap pertama dan tahap kedua. Pada tahap pertama evaluasi dilakukan selama kegiatan untuk melihat kemajuan belajar dan pemahaman pelaku usaha terhadap materi yang sudah diberikan. Pada tahap kedua evaluasi dilakukan setelah pengabdian, maksimal 1 bulan setelah kegiatan berakhir. Kegiatan ini bertujuan untuk memantau perkembangan kemampuan dan kemajuan usaha dari pelaku usaha setelah menggunakan digital marketing, dibanding sebelum adanya pelatihan.

\section{HASIL ATAU PEMBAHASAN}

\section{Prakegiatan}

Tahap prakegiatan ini dilakukan oleh mahasiswa melalui wawancara dengan aparat desa tentang demografi, kependudukan dan kondisi lingkungan di kelurahan Solokpandan. Hasil observasi yang telah dilakukan diketahui bahwa sebagian besar masyarakat berprofesi sebagai pedagang atau didominasi oleh pelaku Usaha Mikro, Kecil, dan Menengah (UMKM) dan Ultra Mikro, seperti pelaku usaha makanan skala rumahan, seperti : keripik singkong, keripik tempe, 
makanan ringan, penjual lele segar dan bakso celup (baslup), serta banyak lagi pelaku usaha mikro lainnya.

Setelah tahap wawancara dan observasi dilakukan oleh mahasiswa, kemudian dilakukan diskusi dengan dosen pendamping agar kegiatan difokuskan kepada salah satu pelaku UMKM Umi yang berpotensi dikembangkan usahanya. Hasil diskusi kami memutuskan untuk fokus pada pelaku usaha kripik singkong Ador, yang berada di jalan Atikah RT.002/RW.07. Ibu lyar selaku pemilik usaha Keripik Singkong Ador sudah menjalankan usahanya sejak tahun 2015. Hasil survey ke tempat usaha bu lyar ditemukan beberapa permasalahan, yaitu : Teknik produksi singkong yang masih sederhana/manual, kemasan yang digunakan masih sangat sederhana dan teknik pemasaran dilakukan dari mulut ke mulut.

Berdasarkan hasil survey ke tempat usaha bu lyar, maka mahasiswa dan dosen pembimbing lapangan mengambil keputusan untuk melaksanakan program pelatihan dan pendampingan terhadap usaha keripik singkong Ador, untuk melakukan pelatihan dan pendampingan wirausaha berbasis digital marketing.

\section{Pelaksanaan}

Tahap pelaksanaan kegiatan diawali dengan pendampingan langsung pelaku usaha mikro dan Dosen memberikan pelatihan dan menjelaskan beberapa materi seperti definisi internet, cara menggunakan dan keuntungan digital marketing, maupun teknik membuat foto produk yang menarik agar lebih menjual ketika di iklankan di marketplace maupun sosial media. Sesi berikutnya adalah pemberian motivasi berwirausaha, hal ini bertujuan untuk memperkuat jiwa kewirausahaan. Tahap akhir dari kegiatan pengabdian ini adalah monitoring dan evaluasi yang dilakukan dalam dua tahap oleh mahasiwa, yaitu tahap pertama dan tahap kedua. Tahap pertama dilakukan setelah pendampingan dan pelatihan dilakukan sampai berakhirnya masa KKN KWU. Pelaku usaha keripik singkong Ador dikunjungi dua hari sekali oleh mahasiswa untuk melihat perkembangan bisnis dan pemakaian akun digital oleh pelaku usaha. Monitoring tahap kedua dilakukan setelah kegiatan KKN telah selesai, mahasiswa mengunjungi pelaku usaha untuk melihat perkembangan usaha keripik singkong Ador.

Berdasarkan hasil wawancara dan survey yang sudah dilakukan pada tahap prakegiatan didapatkan penjelasan bahwa UMKM Umi Keripik Singkong Ador merupakan usaha yang berpotensi untuk dikembangkan secara luas, karena rasanya yang sangat renyah dan tampilan keripik yang menggugah selera. Namun disisi lain masih terdapat kendala dalam pengembangan usaha ini karena teknologi produksi dan pemasaran yang masih sangat sederhana (Gambar 1).

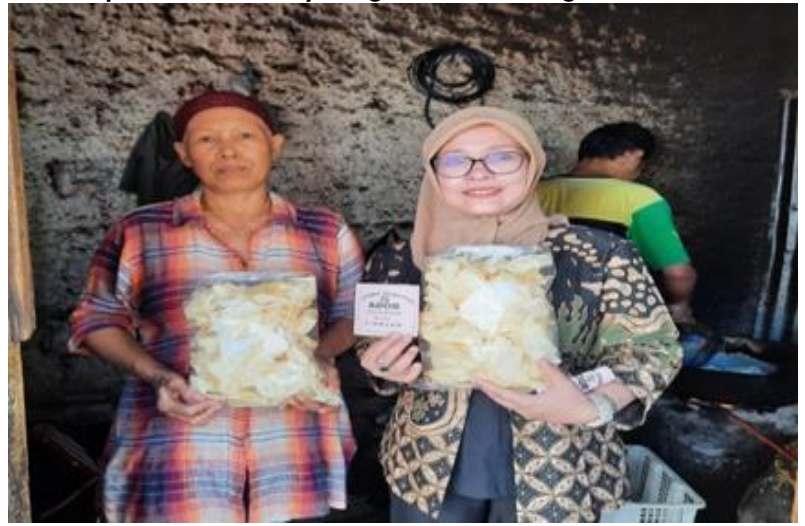

Gambar 1. Survey ke UMKM Umi Keripik Singkong Ador 
Kemasan yang digunakan masih sangat sederhana. Selain itu pelaku usaha belum mempunyai motivasi yang kuat untuk mengembangkan usahanya, dikarenakan kurangnya pengetahuan tentang pengembangan produk dan strategi pemasaran. Berdasarkan fakta atau temuan sebelumnya, diketahui bahwa pelaku usaha masih berorientasi bisnis jangka pendek, karena belum mempunyai roadmap bisnis jangka panjang atau kedepannya. Belum ada daya kreativitas untuk mengembangkan bisnis secara online.

Pada tahap pelaksanaan kegiatan dosen pendamping bersama mahasiswa melakukan pelatihan di kantor kelurahan dan di tempat usaha kripik singkong Ador. Kegiatan pelatihan dilakukan selama satu minggu karena pemahaman dari pelaku usaha tentang penggunaan Android yang masih sangat terbatas. Untuk membantu merubah tampilan produk agar terlihat lebih menarik, mahasiwa yang terlibat membuatkan desain kemasan dan foto produk yang baru (Gambar 2a dan $2 b)$.
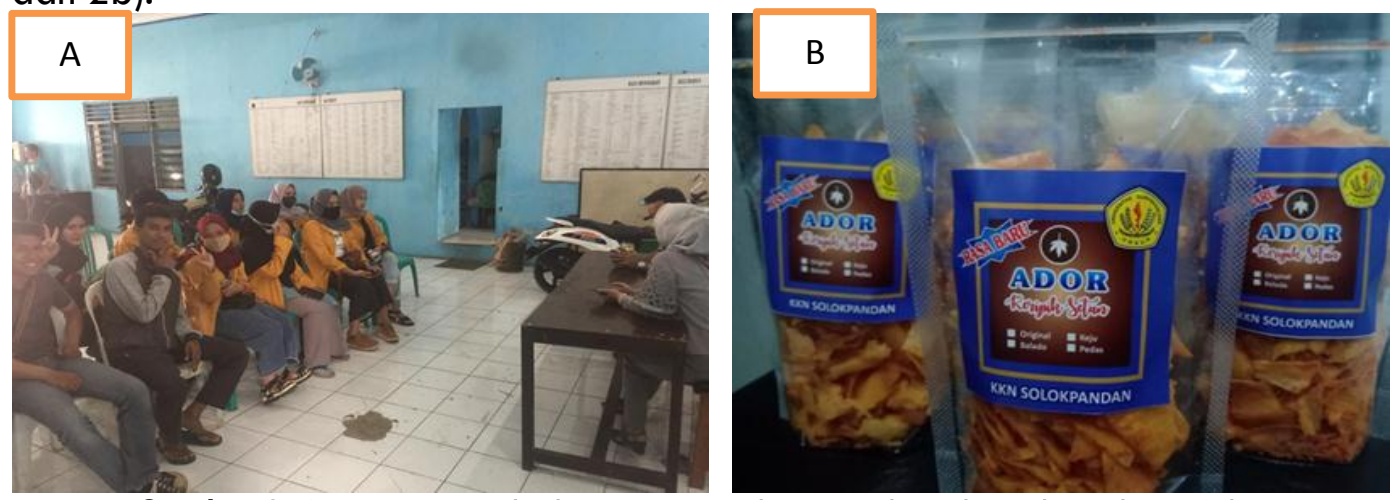

Gambar 2. A. Kegiatan pelatihan, B. Desain kemasan baru keripik singkong Ador

Kegiatan pengabdian ini telah berhasil mendampingi pelaku usaha Ultra Mikro sehingga mampu memanfaatkan internet dan media digital dalam rangka membangun strategi pemasaran yang lebih efektif dan efisien sehingga usaha yang dirintis mampu menghadapi persaingan di pasar global.

\section{Kendala}

Berdasarkan kegiatan pengabdian yang telah dilakukan selama satu bulan di kelurahan Solokpandan menunjukkan bahwa tedapat beberapa permasalahan yang menjadi penyebab tidak berkembangnya UMKM Umi, diantaranya adalah : Kurangnya permodalan bagi pelaku usaha sehingga mereka sulit untuk bangkit dari keterpurukan ekonomi akibat terdampak Covid-19 dan kurangnya pengetahuan pelaku usaha mikro dalam penggunaan internet. Beberapa solusi yang bisa ditawarkan adalah menyaranka pelaku UMKM Umi untuk mendaftarkan usaha mereka ke kelurahan agar mendapatkan surat izin berusaha, sehingga mereka bisa mengakses bantuan dari pemerintah. Solusi selanjutnya adalah meningkatkan peran pemerintahan daerah untuk memberikan bimbingan kepada pelaku usaha dalam mengembangkan usahanya, seperti diadakannya sarana dan prasarana pelatihan kewirausahaan.

\section{PENUTUP}

1. Kesimpulan

Kegiatan KKN KWU yang dilaksanakan di daerah masing-masing mahasiswa telah mampu memberikan pengalaman tersendiri bagi pribadi mahasiswa dan juga memberikan dampak perubahan terhadap pelaku usaha UMKM Ultra Mikro (UMi). Beberapa dampak yang dirasakan adalah berubahnya pola fikir pelaku usaha yang tadi hanya mengandalkan teknik penjualan konvensional sekarang 
sudah mulai menggunakan digital marketing dengan desain kemasan dan fotofoto produk yang menarik.

2. Saran

Berdasarkan kegiatan pengabdian yang sudah dilakukan maka penulis menyarankan agar kegiatan serupa seharusnya dilaksanakan secara kontinyu untuk meningkatkan pengetahuan para pengusaha UMKM terutama mengenai teknik pemasaran secara digital. Kegiatan juga dapat dilakukan bersama dengan instansi terkait.

\section{E. UCAPAN TERIMA KASIH.}

Penulis ucapkan terima kasih kepada Rektor Universitas Suryakancana beserta jajarannya, atas segala support serta fasilitas yang diberikan demi kelancaran kegiatan KKN KWU ini. Ucapan terima kasihpun kami sampaikan pada Bapak Lurah dan ketua RT/RW, ibu-ibu PKK, dan Pemuda KarangTaruna, semua pelaku Usaha serta masyarakat kelurahan Solokpandan dan pihak-pihak yang memberikan kesempatan bagi kami untuk melakukan kegiatan KKN di lingkungan kelurahan Solokpandan

\section{F. DAFTAR PUSTAKA.}

Aisyah, S. (2020). Laporan Penelitian Dampak Pandemi COVID-19 Bagi UMKM Serta Strategi E-Marketing UMKM di Indonesia. Fakultas Ekonomi Dan Bisnis Islam Universitas Islam Negeri Sumatera Utara. http://repository.uinsu.ac.id/10168/1/LAPORAN PENELITIAN - SITI AISYAH\%2C M.M.pdf

Aris Fatoni \& Iwan Setyawan. (2020). Pemberdayaan Ekonomi Bagi Anggota Majelis Taqorrub Ilallah (MTI) Bekasi Melalui Pelatihan Kewirausahaan. Jurnal Pengabdian Teratai, 1(2), 1 10-124.

Farell, G., Thamrin, T., \& Novid, I. (2019). Pelatihan Pemanfaatan Digital Marketing Dalam Pengembangan Pemasaran Dan Kewirausahaan UKM Pada Kota Sawahlunto. Suluah Bendang: Jurnal Ilmiah Pengabdian Kepada Masyarakat, 19(1), 42. https://doi.org/10.24036/sb.0310

Irwan Ch, Andari, T. T., \& Mukmi, M. N. (2020). Laporan Akhir Penelitian Terapan Unggulan Perguruan Tinggi: Strategi Pengembangan Usaha Ekonomi Produktif (UEP) Kelompok Usaha Bersama (KUBe) Dengan Pendekatan Kewirausahaan Di Kota Bukittinggi Propinsi Sumatera Barat. Unida Press. http://repository.unida.ac.id/126/1/Buku Laporan Hasil Penelitian Lengkap for Lap. Akhir 2020.pdf

Pakpahan, A. (2020). Covid-19 Dan Implikasi Bagi Usaha Mikro, Kecil, Dan Menengah. Jurnal Ilmiah Hubungan Internasional, 0(0), 59-64. https://doi.org/10.26593/jihi.v0i0.3870.59-64

Prajanti, S. D. W., Sumastuti, E., Purwani, T., Soliha, E., Oktavilia, S., Rahutami, A. I., \& Mutamimah (Eds.). (2021). UMKM Jejak, Aksi dan Solusi Saat Pandemi Sebuah Antologi ISEI Bagi Negeri. Fastindo.

Syairozi, M. I., \& Susanti, I. (2018). Analisis Jumlah Pengangguran dan Ketenagakerjaan terhadap Keberadaan Usaha Mikro Kecil dan Menengah di Kabupaten Pasuruan. Jurnal Samudra Ekonomi Dan Bisnis, 9(2), 198-208. https://doi.org/10.33059/iseb.v9i2.768

Thaha, A. F. (2020). Dampak Covid-19 Terhadap UMKM di Indonesia. Jurnal Brand, 2(1), 147-153. 